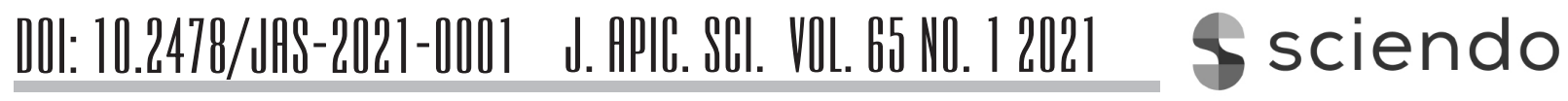

Original Article

\title{
SCREENING AND BIOGUIDED FRACTIONATION OF MIMOSA PIGRA L. BEE POLLEN WITH ANTIOXIDANT AND ANTI-TYROSINASE ACTIVITIES
}

\author{
Phanthiwa Khongkarat ${ }^{1}$ \\ Rico Ramadhan ${ }^{2,3}$ \\ Preecha Phuwapraisirisan ${ }^{4}$ \\ Chanpen Chanchao ${ }^{5 *}$ \\ ${ }^{1}$ Program in Biotechnology, Faculty of Science, Chulalongkorn University, \\ 254 Phayathai Road, Bangkok 10330, Thailand \\ 2Department of Chemistry, Faculty of Science and Technology, Airlangga \\ University, Surabaya, Indonesia \\ ${ }^{3}$ Division of Exploration and Synthesis of Bioactive Compounds, Research Center \\ for Bio-Molecule Engineering, Airlangga University, Surabaya, Indonesia \\ ${ }^{4}$ Department of Chemistry, Faculty of Science, Chulalongkorn University, \\ 254 Phayathai Road, Bangkok 10330, Thailand \\ ${ }^{5}$ Department of Biology, Faculty of Science, Chulalongkorn University, \\ 254 Phayathai Road, Bangkok 10330, Thailand \\ *corresponding author: chanpen.c@chula.ac.th \\ Received: 11 June 2019; accepted: 09 November 2020
}

A bstract

Bee pollen, one of the economic bee products, is widely known as a nutritional food with many bioactivities that depend on many such factors as bee species, plant source and biogeography. For this study, bee pollen was collected from Apis mellifera, harvested from the flowers of mimosa (Mimosa pigra L.) in the Chiang Mai province, Thailand. The sample was extracted in methanol $(\mathrm{MeOH})$ and then sequentially partitioned with hexane, dichloromethane (DCM) and $\mathrm{MeOH}$ in order to isolate compounds depending on their polarities. The obtained extracts were then tested for their antioxidant and antityrosinase activities through 1,1-diphyenyl-2-picrylhydrazyl (DPPH) assay and for/through inhibition of mushroom tyrosinase extract, respectively. The DCM partitioned extract of mimosa flower bee pollen (DCMMBP) provided the highest antioxidant activity, with an effective concentration at $50 \%\left(E C_{50}\right)$ of $192.1 \mu \mathrm{g} / \mathrm{mL}$, and was further fractionated by silica gel 60 column chromatography and Sephadex LH20 size exclusion chromatography. All fractions were tested for their antioxidant activity and analyzed for the chemical structure through nuclear magnetic resonance (NMR). The most active fraction (EC ${ }_{50}$ of $121.3 \mu \mathrm{g} / \mathrm{mL}$ ) was a mixture of compounds, but the isolated flavonoid, naringenin, had a negligible antioxidant activity. In contrast, all three partitioned extracts and pooled fractions after silica gel 60 column chromatography provided no anti-tyrosinase activity $\left(\mathrm{IC}_{50}\right.$ of $>500 \mu \mathrm{g} / \mathrm{mL}$ ) and a very low percentage of tyrosinase inhibition (0-2.99 $\pm 3.18 \%$ ), compared to kojic acid ( $\mathrm{IC}_{50}$ of $8.58 \mu \mathrm{g} / \mathrm{mL}$ and tyrosinase inhibition of $74.2 \pm 1.25 \%$ ).

Keywords: bee pollen, chromatography, mimosa, naringenin, partitioned extract

\section{INTRODUCTION}

Bee pollen, mixture of pollen mixed with a small amount of nectar or even honey (brought from the hive), varies depending on the biogeographic (regional) origin, plant species, bee species and the season (Negrão \& Orsi, 2018). Although the chemical compounds of bee pollen are diverse, the major components generally include proteins, essential amino acids, reducing sugars, lipids, nucleic acids (especially RNA) and crude fiber. The minor components are minerals (e.g. $\mathrm{Ca}, \mathrm{Mg}$ and $\mathrm{Fe}$ ), vitamins (e.g. B-carotene, tocopherol and niacin), enzymes or co-enzymes and bioactive substances (terpenes and polyphenols, which are mainly flavonoids) (Donkersley 
et al., 2017; Denisow \& Denisow-Pietrzyk, 2016; de Arruda et al., 2013; Morgano et al., 2012).

For decades, bee products in both crude and purified forms have been reported to have beneficial bioactivities, including reported antiinflammatory activity in Brassica campestris L., Camellia sinensis L. and Nelumbo nucifera Gaertn. bee pollen (Li et al., 2017), antihypertensive activity in Cistus ladaniferus bee pollen (Nagai et al., 2007), strong cytotoxicity against human prostate cancer $\mathrm{PC}-3$ cells in $B$. campestris L. bee pollen (Wu \& Lou, 2007) and antimicrobial activity in the pollen of Helianthus annuusL. and a commercial bee pollen (Fatrcová-Šramková et al., 2016; Pascoal et al., 2014). In addition, in vitro antioxidant and mushroom tyrosinase inhibitory activities were reported for the bee pollen harvested from Brassica napus L. (Sun et al., 2017).

In our daily life, free radicals and other reactive oxygen species (ROS) can be derived either from normal essential metabolic processes or from such external sources as ultraviolet (UV) rays, air pollutants and industrial chemicals. Increased ROS levels cause oxidative stress and later lead to several diseases, including cancer, atherosclerosis and Alzheimer's disease (Lobo et al., 2010).

Furthermore, in response to UV B (UVB) irradiation, under normal physiological conditions, skin pigment plays an important role in photo-protection against harmful UV injury (Pillaiyar et al., 2017). However, over-production of melanin can occur, which can cause socially undesirable such aesthetics, as dark-looking skin and freckles, as well as more serious effects like melisma and malignant melanoma.

Thus, both the antioxidant and anti-tyrosinase activities are widely accepted to be indicators of anti-melanogenesis. Many skin whitening agents exhibit anti-melanogenic effects through antioxidant and direct inhibition of tyrosinase activity or regulation of tyrosinase expression (Sun et al., 2017). Although the human body produces some antioxidants, many are obtained only from the diet (Lobo et al., 2010). Moreover, many tyrosinase inhibitors used as skin-whitening agents are found naturally in vegetables and fruits (Ebanks et al., 2009; Bernard \& Berthon, 2000; Fan et al., 2017). The phenolic extracts of bee pollen harvested from rape flowers contained a high content of rutin and exhibited high in vitro antioxidant and mushroom tyrosinase inhibitory activities (Sun et al., 2017). From the available data, bee pollen from monofloral sources could be an alternative source for antioxidant and anti-tyrosinase activities. In this work, monofloral bee pollen, harvested from mimosa (Mimosa pigral.) flowers by $A$. mellifera, was selected for extraction and partition. The more active fractions were further enriched and analyzed for their chemical composition by nuclear magnetic resonance (NMR). The aim of the study was the testing of antioxidant and anti-tyrosinase activity of monofloral bee pollen of Mimosa pigra L. harvested in Thailand.

\section{MATERIAL AND METHODS}

Sample collection and morphological identification of the bee pollen

The bee pollen used in this study was collected from $A$. mellifera that had access to mimosa (Mimosa pigra L.) flowers in the Chiangmai province, Thailand in 2017. The pollen was stored at room temperature until further analysis. A small amount of dry bee pollen was investigated with a scanning electron microscope (SEM). The morphology and characteristics of the bee pollen was recorded under SEM at 5,000X magnification. Our findings were compared to the identification results described for that plant species by Caccavari (2002) and El Ghazali et al. (1997). The sample was then prepared according to the procedure as described in details in the following subsections. The overall extraction and enrichment procedure are shown in Fig. 1.

\section{Crude extraction and partition}

The bee pollen (140 g) was mixed with $800 \mathrm{~mL}$ of methanol $(\mathrm{MeOH})$, shaken at $100 \mathrm{rpm}, 15^{\circ} \mathrm{C}$ for $18 \mathrm{~h}$, and then centrifuged at $5500 \mathrm{rpm}$, $4^{\circ} \mathrm{C}$ for $15 \mathrm{~min}$. The supernatant was collected while the solid residue (pellet) was re-extracted 


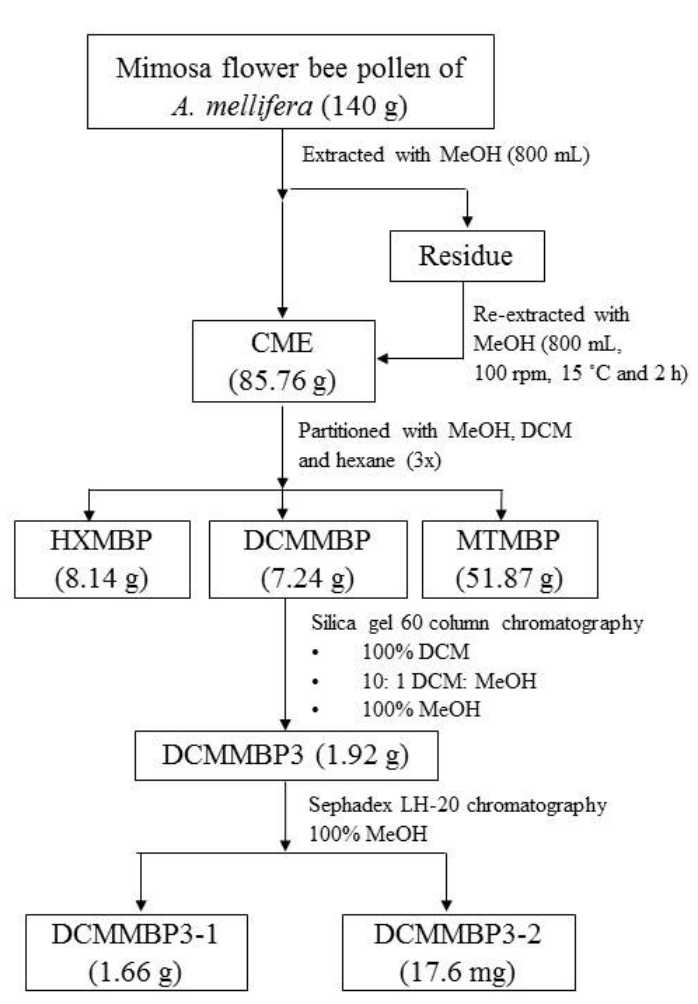

Fig. 1. Summarized procedure for the extraction and enrichment of antioxidants from mimosa flower bee pollen.

three more times in the same manner with $800 \mathrm{~mL}$ of $\mathrm{MeOH}$ each time. The four $\mathrm{MeOH}$ extracts were combined together and the solvent evaporated under reduced pressure at a maximum temperature of $40-45^{\circ} \mathrm{C}$ to yield the crude $\mathrm{MeOH}$ extract of mimosa flower bee pollen (CME). The CME was kept at $-20^{\circ} \mathrm{C}$ in the dark until used.

The CME was sequentially partitioned by $\mathrm{MeOH}$ (high polarity), dichloromethane (DCM; medium polarity) and hexane (low polarity). To this end, the CME was dissolved in $\mathrm{MeOH}$ until it was not sticky and then mixed with an equal volume of hexane in a separating funnel and left to phase separate, whereupon the upper hexane phase was collected. The lower $\mathrm{MeOH}$ phase was then further extracted with hexane in the same manner twice more, and the hexane extracts were pooled and evaporated under reduced pressure at a maximum temperature of $40-45^{\circ} \mathrm{C}$ to yield the hexane partitioned extract of mimosa flower bee pollen (HXMBP). Meanwhile, the residual $\mathrm{MeOH}$ phase was then extracted with an equal volume of DCM three times in the same manner as above (except the DCM phase was the lower layer), with the pooled DCM extracts evaporated as above to yield the DCM partitioned extract of mimosa flower bee pollen (DCMMBP). Finally, the residual $\mathrm{MeOH}$ phase was evaporated as above to yield the $\mathrm{MeOH}$ partitioned extract of mimosa flower bee pollen (MTMBP). All three partitioned extracts were tested for their antioxidant and anti-tyrosinase activities as detailed below.

\section{Antioxidant activity}

The 1,1-diphenyl-2-picrylhydrazyl (DPPH) assay, modified from Chantarudee et al. (2012), was used to assay the antioxidant activity. Five different concentrations of each sample were prepared in dimethyl sulfoxide (DMSO). For each concentration, $20 \mu \mathrm{L}$ of the sample was mixed with $80 \mu \mathrm{L}$ of $0.15 \mathrm{mM}$ DPPH in $\mathrm{MeOH}$ and incubated at room temperature for $30 \mathrm{~min}$. The absorbance was measured at $517 \mathrm{~nm}\left(\mathrm{~A}_{517}\right)$ using a microplate reader. Ascorbic acid (vitamin C) was used as the standard reference. The antioxidant activity and the effective concentration at 50\% (EC $\left.{ }_{50}\right)$ were then calculated as mentioned in Chantarudee et al. (2012).

\section{Anti-tyrosinase activity}

The anti-tyrosinase activity was determined as reported by Zhang et al. (2015) with minor modifications. Five different concentrations of the sample in DMSO were prepared. The reaction mixture contained $120 \mu \mathrm{L}$ of $2.5 \mathrm{mM} \mathrm{L-3,4-di-}$ hydroxyphenylalanine (L-DOPA) in a phosphate buffer, $30 \mu \mathrm{L}$ of $80 \mathrm{mM}$ phosphate buffer $(\mathrm{pH}$ 6.8) and $10 \mu \mathrm{L}$ of the sample solution in DMSO. The mixtures were mixed and then pre-incubated at $25^{\circ} \mathrm{C}$ for $10 \mathrm{~min}$ before $40 \mu \mathrm{L}$ of mushroom tyrosinase (165 units/mL) in phosphate buffer was added and incubated at $25^{\circ} \mathrm{C}$ for $5 \mathrm{~min}$. The absorbance of the sample was measured at $475 \mathrm{~nm}\left(\mathrm{~A}_{475}\right)$ using a microplate reader. Kojic acid was used as the positive diphenolase inhibitor standard. Each sample was performed and measured in triplicate. The tyrosinase inhibition (\%) and the inhibitory concentration at $50 \%\left(\mathrm{IC}_{50}\right)$ were calculated as mentioned in Zhang et al. (2015). 


\section{Enrichment of active fractions \\ Silica gel 60 column chromatography \\ (SiG60-CC)}

The extract with the highest antioxidant activity (DCMMBP) was selected for fractionation by SiG60-CC. The 500-mL column was packed with fine SiG60 (Merck, for column chromatography). The DCMMBP partitioned extract (7.24 g) was dissolved in $40 \mathrm{~mL}$ of $\mathrm{MeOH}$ and combined with $20 \mathrm{~g}$ of rough SiG60 (Merck for CC). When dry, it was poured over the surface of the packed SiG60 column and then firstly eluted with $500 \mathrm{~mL}$ of DCM, followed by 2,000 mL of 10:1 (v/v) DCM: $\mathrm{MeOH}$ and then $1,000 \mathrm{~mL}$ of $\mathrm{MeOH}$, respectively. Eluted fractions (10 $\mathrm{mL}$ each) were collected, and the solvent was removed by evaporation under reduced pressure at a maximum temperature of $40-45^{\circ} \mathrm{C}$. The pattern of chemical compounds in each fraction was profiled by thin layer chromatography (TLC; see below). Fractions with the same TLC pattern were assumed to be chemically similar and were pooled. Each fraction, or pooled fraction, was then tested for its antioxidant activity using the DPPH assay as above.

\section{Sephadex LH-20 size exclusion CC}

Sephadex LH-20 gel was immersed in absolute $\mathrm{MeOH}$ overnight to allow the beads to swell. Cotton was placed at the bottom of a $250-\mathrm{mL}$ column and the swollen Sephadex LH-20 gel was packed into the column to $4 / 5$ of the column height. The active fraction was dissolved in absolute $\mathrm{MeOH}$ until it was not too viscous and then loaded carefully onto the top of the Sephadex LH-20 gel using a Pasteur pipette, with the packed column valve open to allow the partitioned extract to be absorbed into the gel. The column was then eluted with $500 \mathrm{~mL}$ of absolute $\mathrm{MeOH}$, collecting $5 \mathrm{~mL}$ fractions. A small amount of each fraction was resolved by TLC (see above) and fractions with a similar TLC profile were pooled. All fractions or pooled fractions were then evaluated for their antioxidant activity using the DPPH assay as above.

\section{Comparison of principal components of fractions by TLC}

A $5 \times 5 \mathrm{~cm}^{2}$ TLC plate with silica as the immobile phase was prepared. The test sample was spotted onto the solvent front line of the plate by a capillary tube, allowed to dry at room temperature, and then resolved in one direction using the appropriate mobile phase solvent of (a) 10:1 (v/v) DCM: MeOH or (b) 10:0.5:1 (v/v/v) DCM: ethyl acetate (EtOAc): $\mathrm{MeOH}$. The resolved compounds on the TLC plate were visualized under UV light at $254 \mathrm{~nm}$ or by dipping in 3\% ( v/v) anisaldehyde in $\mathrm{MeOH}$ and heating over a hot plate. The identification of the yellow solid compound in fraction DCMMBP3-2, named compound I, was done based on the chemical structure analysis (NMR) and based on the comparison to the flavonoid isolated from the aerial parts of Cyclotrichium origanifolium (Guzel et al., 2017).

\section{Chemical structure analysis by NMR}

Each enriched fraction was evaporated and analysed. Briefly, the evaporated sample was dissolved in an appropriate deuterated solvent (MeOH-D4, Merck) at a ratio of $5-20 \mathrm{mg}$ of compound to $600 \mu \mathrm{L}$ of deuterated solvent. It was then transferred to an NMR tube and shaken until well combined. The NMR spectrum was recorded by a Varian Mercury plus 400 machine operated at $400 \mathrm{MHz}$ for ${ }^{1} \mathrm{H}-\mathrm{NMR}$ and a Bruker AVANCEIII $400 \mathrm{MHz}$ machine for ${ }^{13} \mathrm{C}-\mathrm{NMR}$ nuclei in order to detect the functional groups using tetramethylsilane as the internal standard. The chemical shift in $\delta$ (ppm) was assigned with reference to the signal from the residual protons in the deuterated solvents, while the chemical shift and J coupling value were determined using the MestReNova version 12.0.3 software.

\section{Data analysis}

Experiments were performed in triplicate. Numerical data are reported as the mean \pm standard deviation $( \pm \mathrm{SD})$, determined in the Microsoft Excel 2016 software. 


\section{RESULTS}

Morphological identification of the bee pollen Under SEM, the morphology of the mimosa (Mimosa pigraL.) flower bee pollen was observed to be from oblate to spherical in shape with four (tetrad) pollen subunits (Fig. 2).

Antioxidant and anti-tyrosinase activity of crude and partitioned extracts of bee pollen

The characteristics (weight, yield and appearance) for crude (CME) and partitioned extracts (MTMBP, DCMMBP, HXMBP) are presented in the Tab. 1. The results for the antioxidant and anti-tyrosinase activity of these bee pollen extracts, are also introduced in the Tab. 1.

For their antioxidant activity, the obtained $\mathrm{EC}_{50}$ values are shown in comparison to that for ascorbic acid as the standard reference. Only the DCMMBP extract was the most active $\left(E_{50}\right.$ of $192.1 \mu \mathrm{g} / \mathrm{mL})$, although this was still an over two-fold higher $\mathrm{EC}_{50}$ value (so less effective) than ascorbic acid ( $E C_{50}$ of $89.8 \mu \mathrm{g} / \mathrm{mL}$ ).

The three partitioned extracts were also tested for their tyrosinase inhibitory activity, with the obtained $I_{50}$ values shown in Tab. 1 in comparison with that for kojic acid as the standard reference. None of the crude extracts showed any notable anti-tyrosinase activity, with $\mathrm{IC}_{50}$ values of $>500 \mu \mathrm{g} / \mathrm{mL}$ compared to $8.58 \mu \mathrm{g} / \mathrm{mL}$ for kojic acid.

Antioxidant and anti-tyrosinase activity of active compounds from DCMMBP

Fractionation of DCMMBP by SiG60-CC and Sephadex LH-20 size exclusion CC

Since the DCMMBP provided the best antioxidant activity (192.1 $\mu \mathrm{g} / \mathrm{mL})$, it was further fractionated by SiG60-CC. From 7.24 g of DCMMBP a total of ninety-six fractions were collected. After a comparison of the TLC profiles and pooling fractions with a similar pattern, three different fractions (DCMMBP1-3) were obtained. Their weight, yield and appearance are summarized in Tab. 2. These three pooled fractions were then tested for their antioxidant activity, with the derived $\mathrm{EC}_{50}$ values reported in Tab. 2. Fraction DCMMBP3 gave the highest antioxidant activity $\left(\mathrm{EC}_{50}\right.$ of $112.2 \mu \mathrm{g} / \mathrm{mL}$ ) which was only around 1.4-fold higher numerically from that for ascorbic acid $\left(E_{50}\right.$ of $\left.81.1 \mu \mathrm{g} / \mathrm{mL}\right)$.

In addition, fractions DCMMBP1-3 at $50 \mu \mathrm{g} / \mathrm{mL}$ were tested for their anti-tyrosinase activity, with the obtained results shown in Tab. 2. All

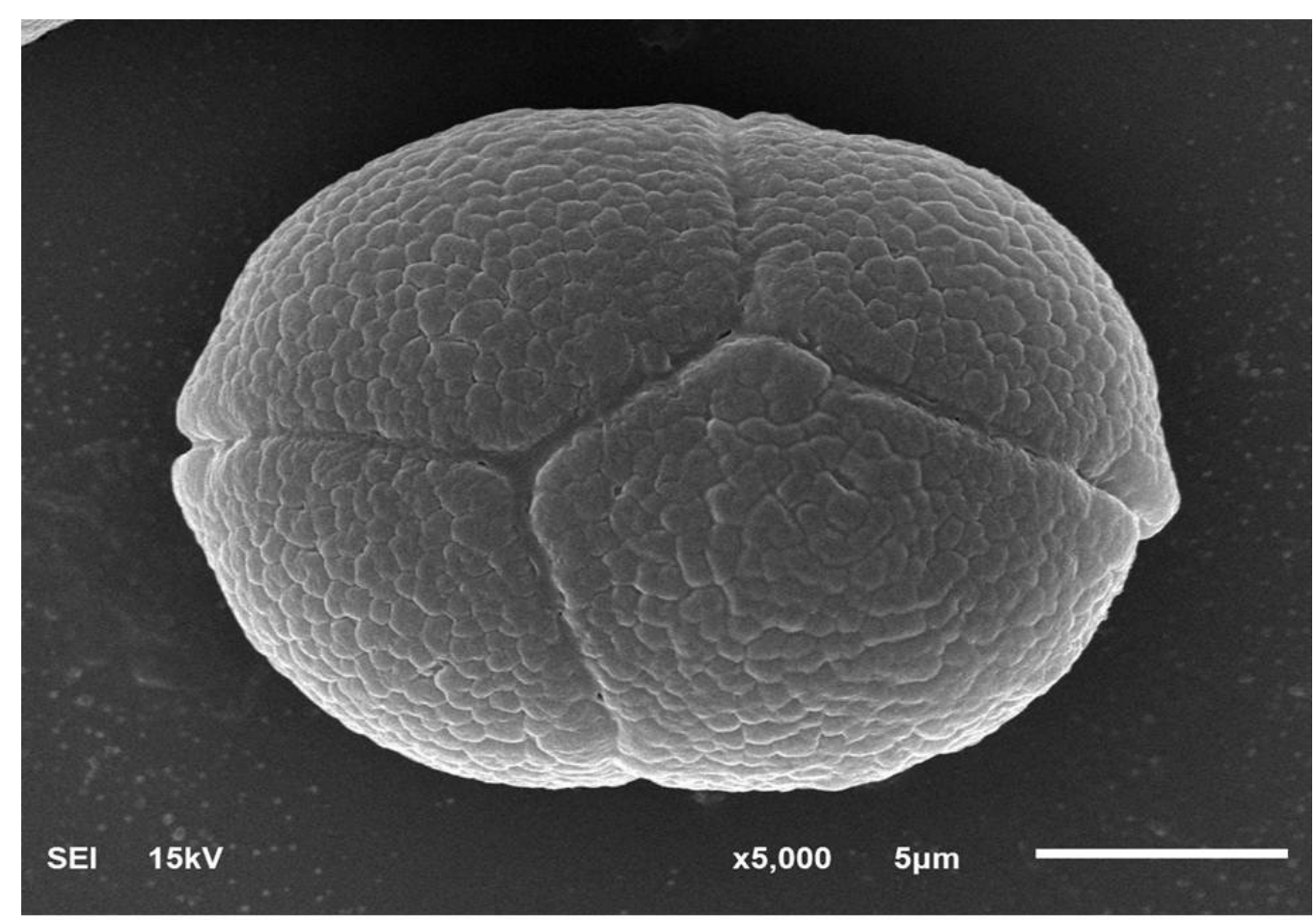

Fig. 2. Morphology of the mimosa flower (Mimosa pigra L.) bee pollen under scanning electron microscopy at $5,000 X$ magnification. Images shown are representative of at least 100 pollen grains observed per sample. 
Table 1.

Characteristics, antioxidant ( $\mathrm{EC}_{50}$ value) and anti-tyrosinase (IC $\mathrm{C}_{50}$ value) activities of the crude (CME) and partitioned (MTMBP, DCMMBP and HXMBP) bee pollen extracts

\begin{tabular}{cccccc}
\hline Sample & $\begin{array}{c}\text { Weight } \\
(\mathrm{g})\end{array}$ & $\begin{array}{c}\text { Yield } \\
(\%)\end{array}$ & Appearance & $\begin{array}{c}\mathrm{EC}_{50} \\
(\mu \mathrm{g} / \mathrm{mL})\end{array}$ & $\begin{array}{c}\mathrm{IC}_{50} \\
(\mu \mathrm{g} / \mathrm{mL})\end{array}$ \\
\hline \multicolumn{7}{c}{$\begin{array}{c}\text { Before partition } \\
\text { CME }\end{array}$} & 85.76 & 61.3 & Turbid dark brown oil & - & - \\
\hline MTMBP & 51.87 & 60.5 & Dark brown oil & $>1,000$ & $>500$ \\
DCMMBP & 7.24 & 8.44 & Sticky dark brown solid & $192.1 \pm 17.83$ & $>500$ \\
HXMBP & 8.14 & 9.49 & Dark brown oil & $>1,000$ & $>500$ \\
$\begin{array}{c}\text { Reference } \\
\text { standards }\end{array}$ & & & - & & \\
Ascorbic acid & - & - & - & $89.8 \pm 5.07$ & - \\
Kojic acid & - & - & - & - & $8.58 \pm 0.31$ \\
\hline
\end{tabular}

Data are shown as the mean $\pm S D$, derived from three repeats.

three fractions had a very low anti-tyrosinase activity with essentially no activity (at $50 \mu \mathrm{g} / \mathrm{mL}$ ) for DCMMBP3.

Since fraction number DCMMBP3 provided the best antioxidant activity ( $\mathrm{EC}_{50}$ of $\left.112.2 \mu \mathrm{g} / \mathrm{mL}\right)$, it was further enriched by Sephadex $\mathrm{LH}-20$ size exclusion chromatography to yield a total of sixty-six fractions. After a pooling of fractions with similar TLC profiles, two different fractions (DCMMBP3-1 and DCMMBP3-2) were obtained. Their weight, yield and appearance are summarized in Tab. 2. With respect to their antioxidant activity, fraction DCMMBP3-1 had the highest antioxidant activity $\left(\mathrm{EC}_{50}\right.$ of $121.3 \mu \mathrm{g} / \mathrm{mL}$ ), while DCMMBP3-2 had essentially no antioxidant activity. The antioxidant activity for DCMMBP3-1 (EC ${ }_{50}$ of $\left.121.3 \mu \mathrm{g} / \mathrm{mL}\right)$ was only slightly less powerful than its parental fraction (DCMMBP3; $E_{50}$ of $112.2 \mu \mathrm{g} / \mathrm{mL}$ ) although DCMMBP3-1 accounted for only about 38\% of the antioxidant activity in DCMMBP3 (after taking account of the $58.2 \%$ yield loss from SiG60-CC of DCMMBP and the $12.6 \%$ yield loss from Sephadex-LH2O-CC of DCMMBP-3). It is unclear if this apparent activity loss represents

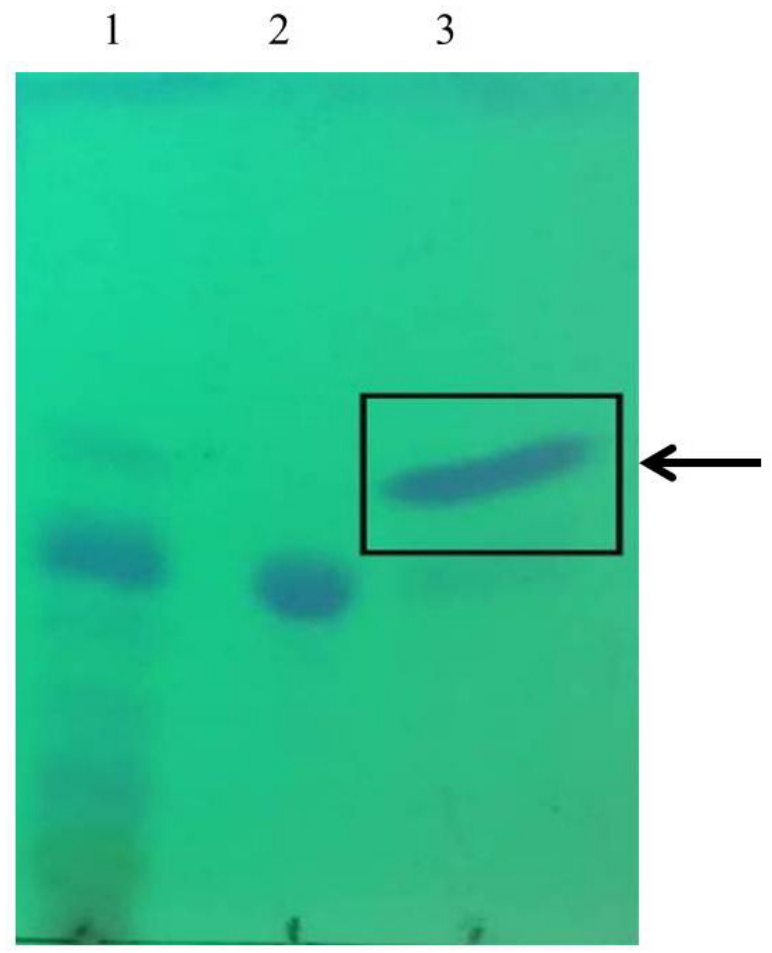

Fig. 3. Representative TLC plate showing the compound profile of DCMMBP (lane 1), DCMMBP3-1 (lane 2) and DCMMBP3-2 (lane 3). The mobile phase was 10: 1 (v/v) DCM: MeOH. Arrow indicates compound I. 
Table 2.

Characteristics, antioxidant (EC50 value) and anti-tyrosinase (\% inhibition) activities of the different pooled fractions of DCMMBP after SiG60-CC and Sephadex LH-20 size exclusion CC

\begin{tabular}{cccccc}
\hline Fraction & $\begin{array}{c}\text { Weight } \\
(\mathrm{g})\end{array}$ & $\begin{array}{c}\text { Yield } \\
(\%)\end{array}$ & Appearance & $\begin{array}{c}\mathrm{EC}_{50} \\
(\mu \mathrm{g} / \mathrm{mL})\end{array}$ & $\begin{array}{c}\text { Tyrosinase } \\
\text { inhibition } \\
(\%)\end{array}$ \\
\hline DCMMBP1 & 0.42 & 5.8 & Sticky dark brown solid & $819.5 \pm 24.37$ & $2.86 \pm 1.75$ \\
DCMMBP2 & 0.69 & 9.5 & Sticky dark brown solid & $284.1 \pm 11.92$ & $2.99 \pm 3.18$ \\
DCMMBP3 & 1.92 & 26.5 & Pale brown solid & $112.2 \pm 1.35$ & 0 \\
Ascorbic acid & - & - & - & $81.1 \pm 1.44$ & - \\
Kojic acid & - & - & - & - & $74.2 \pm 1.2$ \\
\hline & \multicolumn{7}{c}{ After Sephadex LH-20 size exclusion CC } \\
\hline DCMMBP3-1 & 1.6599 & 86.5 & Pale brown solid & $121.3 \pm 8.11$ & - \\
DCMMBP3-2 & 0.0176 & 0.92 & Yellow solid & $>1000$ & - \\
Ascorbic acid & - & - & - & $81.1 \pm 1.44$ & - \\
\hline
\end{tabular}

Data are shown as the mean $\pm S D$, derived from three repeats.

the removal of synergistic compounds or cofactors into DCMMBP3-2 or is simply a yield loss in the CC.

\section{Principal chemical composition analysis (TLC and NMR) of fractions DCMMBP3-1 and DCMMBP3-2}

After Sephadex LH-20 size exclusion CC, the chemical composition of the two obtained fractions was tested by TLC (Fig. 3). The smear on the TLC plate indicated that fraction DCMMBP3-1 seemed to contain more than one chemical component of a similar polarity and molecular weight, and so fraction DCMMBP3-1 was reported as a mixture. In contrast, only a sharp band was observed on the TLC plate for fraction DCMMBP3-2, which indicated it was potentially a pure compound. Therefore, the chemical structure of the compound, named compound $\mathrm{I}$, in fraction DCMMBP3-2 was analyzed by NMR.

Compared to the flavonoid isolated from the aerial parts of Cyclotrichium origanifolium (Guzel et al., 2017), the obtained NMR peaks in the chemical shift pattern were ${ }^{1} \mathrm{H}-\mathrm{NMR}(400 \mathrm{MHz}$, $\left.\mathrm{MeOH}-d_{4}\right)$ \&: 7.30 (d, $\left.=8.5 \mathrm{~Hz}, 2 \mathrm{H}\right), 6.81$ (d, 8.5 $\mathrm{Hz}, 2 \mathrm{H}), 5.88(\mathrm{q}, \jmath=2.2 \mathrm{~Hz}, 2 \mathrm{H}), 5.31$ (dd, $=13.0$,
$3.0 \mathrm{~Hz}, 1 \mathrm{H}), 3.09(\mathrm{dd},=17.1,13.0 \mathrm{~Hz}, 1 \mathrm{H})$ and 2.67 (dd, $=17.1,3.0 \mathrm{~Hz}, 1 \mathrm{H}) .{ }^{13} \mathrm{C}-\mathrm{NMR}(100 \mathrm{MHz}$, $\left.\mathrm{MeOH}-d_{4}\right)$ \&: 197.8, 168.4, 164.9, 159.0, 131.1, 129.0, 116.4, 103.4, 97.1, 96.3, 80.5 and 44.0 (Supplement 1). The compound I was identified as naringenin (Fig. 4).

When the mixed fraction DCMMBP3-1 was analyzed for its chemical structure by NMR the obtained NMR peaks of chemical shift pattern were ${ }^{1} \mathrm{H}-\mathrm{NMR}\left(400 \mathrm{MHz}, \mathrm{MeOH}-d_{4}\right)$ 8: 7.56-7.41 $(\mathrm{m}, 3 \mathrm{H}), 7.39$ (dd, $=9.2,5.5 \mathrm{~Hz}, 1 \mathrm{H}), 7.13-7.05$ $(\mathrm{m}, 2 \mathrm{H}), 7.05-7.02(\mathrm{~m}, 1 \mathrm{H}), 7.02-6.91(\mathrm{~m}, 4 \mathrm{H})$, 6.91-6.65 (m, 7H), 6.40 (ddt, f=20.6, 15.7, $5.5 \mathrm{~Hz}$, $3 \mathrm{H}), 4.64(\mathrm{~s}, 1 \mathrm{H}), 3.86-3.71(\mathrm{~m}, 14 \mathrm{H}), 3.52(\mathrm{~s}, 2 \mathrm{H})$, 3.46 (dd, f=18.5, $7.7 \mathrm{~Hz}, 3 \mathrm{H}), 3.34$ (s, 13H), 1.87 $(\mathrm{dt},=26.9,7.1 \mathrm{~Hz}, 3 \mathrm{H}), 1.67(\mathrm{~s}, 1 \mathrm{H})$ and 1.66-1.51 (m, 4H). ${ }^{13} \mathrm{C}-\mathrm{NMR}\left(100 \mathrm{MHz}, \mathrm{MeOH}-d_{4}\right)$ : : 169.2, 149.8, 149.5, 149.3, 144.7, 142.4, 142.1, 128.6, $128.3,123.5,123.3,121.3,116.6,116.3,115.4$, 112.3, 111.7, 106.9, 106.5, 56.9, 56.6, 56.5, 49.9, 49.7, 49.5, 49.3, 49.1, 48.9, 48.6, 48.4, 47.6, $47.1,45.7,40.2,39.9,38.3,38.1,28.9,27.9$ and 27.7 (Supplement 2). Considering the ${ }^{1} \mathrm{H}$ - and ${ }^{13} \mathrm{C}-\mathrm{NMR}$, a phenol derivative was suggested to be the major compound. 


\section{_ KHONGKRPHT ET Hl. ___ Antioxidant activity of mimosa bee pollen}

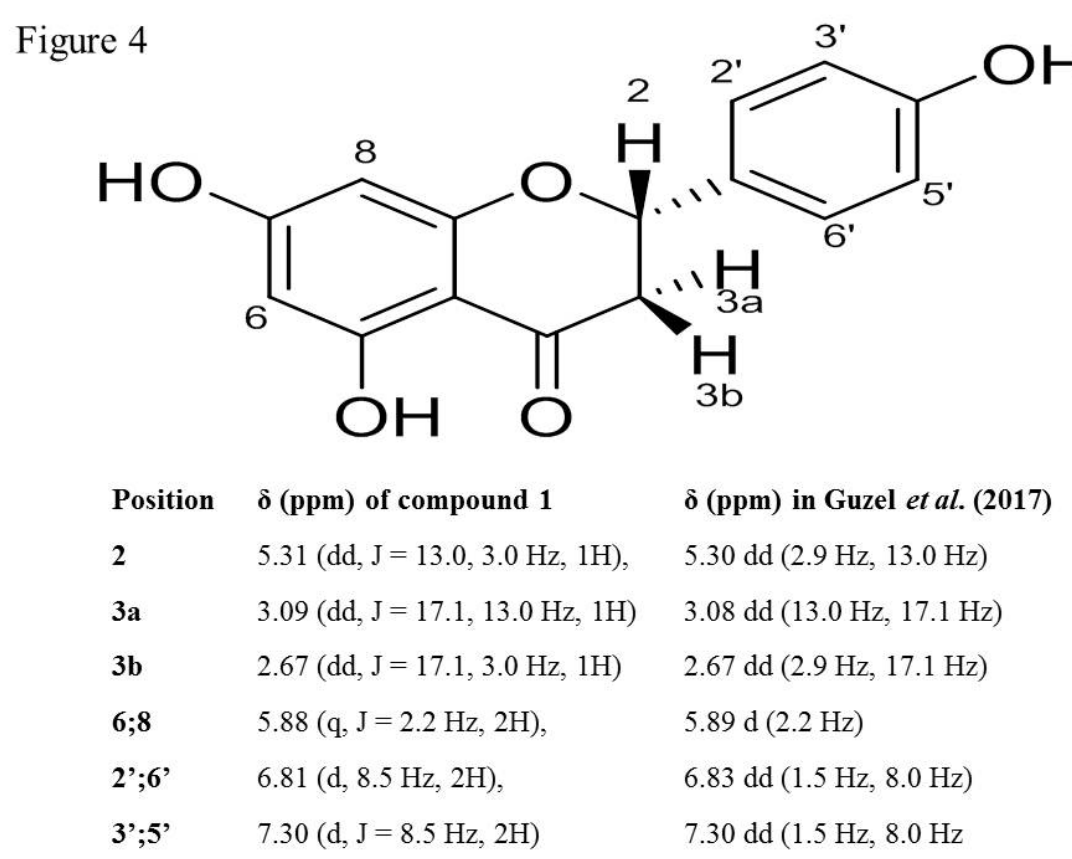

Fig. 4. The structural formula of naringenin (Compound I), found in fraction DCMMBP3-2 from DCMMBP3.

\section{DISCUSSION}

Monofloral and polyfloral bee pollen are widely available, but the former is more popular in dietary supplements because the floral origins of the bee pollen can be identified (Araújo et al., 2017) and so the standard of the monofloral bee pollen can be controlled. In this study, bee pollen from mimosa (Mimosa pigra L.) flowers was chosen because it is widely found in Thailand. The botanical origin was confirmed under SEM, where the morphology in the mimosa bee pollen was the same as that reported for mimosa floral pollen (Caccavari, 2002; El Ghazali et al., 1997).

Both antioxidant and anti-tyrosinase activities have been found in the ethanol extract of many monofloral bee pollens from China (Zhang et al., 2015). However, for the antioxidant activity, the most active crude extract was reported to be that from corn bee pollen (Chantarudee et al., 2012). In addition, in this study, the DCMMBP partitioned extract presented the only strong antioxidant activity, suggesting that the bioactivity depended on the solvent used for extraction and the botanical origin of the bee pollen (Kast et al., 2018).

For the antioxidant activity of bee pollen, naringenin was isolated as a pure compound but found to be essentially inactive, whilst a mixture that contained a high content of polyphenol derivatives was active. However, it is unclear if there is any synergistic effect of these mixed compounds (Araújo et al., 2017; Wang et al., 2018; Nna et al., 2018), including naringenin, which showed no activity alone, or if the reduced total antioxidant activity simply represents loss of compounds in the CC. For example, naringenin was previously reported to show antioxidant activity in the DPPH assay, albeit only weakly and some 60-fold lower than that for quercetin (Choi et al., 2002). This can be explained by the fact that naringenin lacks the C3 hydroxyl group from the flavanol basic moiety and contains a single 4' hydroxyl group and a saturated heterocyclic $C$ ring, leading to a lack of conjugation between the left- and right-side rings. Additionally, metal chelation enhances the antioxidant activity of naringenin and the solvent plays an important role in this enhancement (Uivarosi et al., 2016). Although naringenin provided a low antioxidant activity in this study, it has been reported to have other bioactivities, including hepatoprotective, anti-inflammatory and anticarcinogenic activities (Rao et al., 2017).

The active mixture of fraction DCMMBP3-1 from mimosa flower bee pollen had the highest antioxidant activity in the DPPH assay and likely contains a phenol derivative as a major 
component, as deduced from the ${ }^{1} \mathrm{H}$ - and ${ }^{13} \mathrm{C}-\mathrm{NMR}$ data. As phenolic compounds are known to inhibit the chain reaction of free radicals by donating a hydrogen atom to the free radical, the internal structure of the phenolic compound would then become delocalized by an electron, resulting in a stable molecule. This is consistent with LeBlanc et al. (2009), who reported screening the crude extract of mimosa pollen by both the DPPH and ferric reducing-antioxidant power assays, where a high number of polyphenols was reported.

The tyrosinase inhibitory activity was evaluated using a commercial tyrosinase extracted from champignon mushroom (Agaricus bisporus), since this is highly homologous with mammalian tyrosinases. The notable feature observed in tyrosinases from different sources is that the central copper-binding domain is conserved and contains strictly conserved amino acid residues, including three histidines (Chang, 2009). Therefore, this method can be used as a screening method to search for potential human tyrosinase inhibitors. However, no active antityrosinase compound was obtained in this work in the mimosa bee pollen due to the very low anti-tyrosinase activity in fractions DCMMBP1-3. This was consistent with the almost complete absence of any tyrosinase inhibition activity in the parental CME, suggesting that any significant anti-tyrosinase activity present in mimosa bee pollen is likely to be non-polar compound(s). The results of this study suggest that Mimosa pigra L. flower bee pollen harvested in Thailand could reduce the level of free radicals but not anti-tyrosinase activity. However, more monofloral bee pollen from other floral pollens should be tried. Also, it is recommended that the solvents and methods for enrichment should be optimized to fit the purpose. The potential benefit of this work is that new active antioxidant and anti-tyrosinase compounds could be obtained and developed for use in the pharmaceutical and cosmetic industries. Finally, this may help the local economy through promotion of the bee industry in Thailand.

\section{ACKNOWLEDGEMENTS}

This work was financially supported by the Science Achievement Scholarship of Thailand, the $90^{\text {th }}$ Anniversary of Chulalongkorn University Fund (Ratchadaphiseksomphot Endowment Fund), Sci-Super IV_61_003 and Chulalongkorn University (Ratchadaphiseksomphot Endowment Fund).

\section{REFERENCES}

Araújo, J.S., Chambó, E.D., de Carvalho Costa, M.A.P., da Silva, S.M.P.C., de Carvalho C.A.L., Estevinho, L.M. (2017). Chemical composition and biological activities of mono- and heterofloral bee pollen of different geographical origins. International Journal of Molecular Sciences, 18(5), 921. D0I: 10.3390/ ijms18050921

Bernard, P., \& Berthon, J. (2000). Resveratrol: an original mechanism on tyrosinase inhibition. International Journal of Cosmetic Science, 22(3), 219-226. DOl: 10.1046/j.1467-2494.2000.00019.x

Caccavari, M.A. (2002). Pollen morphology and structure of Tropical and Subtropical American genera of the Piptadenia -group (Leguminosae: Mimosoideae). Grana, 47(3), 130-141. https://doi. org/10.1080/001731302321042597

Chang, T.S. (2009). An updated review of tyrosinase inhibitors. International Journal of Molecular Sciences, 196), 2440-2475. https://doi.org/10.3390/ ijms10062440

Chantarudee, A., Phuwapraisirisan, P., Kimura, K., Okuyama, M., Mori, H., Kimura, A., Chanchao, C. (2012). Chemical constituents and free radical scavenging activity of corn pollen collected from Apis mellifera hives compared to floral corn pollen at Nan, Thailand. BMC Complementary and Alternative Medicine, 12, 45. DOl: 10.1186/1472-6882-12-45

Choi, C.W., Kim, S.C., Hwang, S.S., Choi, B.K., Ahn, H.J., Lee, M.Y.,... Kim, S.S. (2002). Antioxidant activity and free radical scavenging capacity between Korean medicinal plants and flavonoids by assay-guided comparison. Plant Science, 163(6), 1161-1168. 
https://doi.org/10.1016/S0168-9452(02)00332-1

de Arruda, V.A.S., Pereira, A.A.S., de Freitas, A.S., Barth, O.M., de Almeida-Muradian, L.B. (2013). Dried bee pollen: B complex vitamins, physicochemical and botanical composition. Journal of Food Composition and Analysis, 29(2), 100-105. https://doi. org/10.1016/j.jfca.2012.11.004

Denisow, B., \& Denisow-Pietrzyk, M. (2016). Biological and therapeutic properties of bee pollen: a review. Journal of the Science of Food and Agriculture, 96(13), 4303-4309. D0l: 10.1002/jsfa.7729

Donkersley, P., Rhodes, G., Pickup, R.W., Jones, K.C., Power, E.F., Wright, G.A., Wilson, K. (2017). Nutritional composition of honey bee food stores vary with floral composition. Oecologia, 185(4), 749-761. DOl: 10.1007/s00442-017-3968-3

Ebanks, J.P., Wickett, R.R., Boissy, R.E. (2009). Mechanisms regulating skin pigmentation: the rise and fall of complexion coloration. International Journal of Molecular Sciences, 1999), 4066-4087. DOl: 10.3390/ijms10094066

El Ghazali G.E.B., Satti, A.M., Tsuji, S.-I. (1997). Intraspecific pollen polymorphism in Mimosa pigra (Mimosaceae). Grana, 36(5), 279-283. DOl: 10.1080/00173139709362617

Fan, M., Zhang, G., Hu, X., Xu, X., Gong, D. (2017). Quercetin as a tyrosinase inhibitor: inhibitory activity, conformational change and mechanism. Food Research International, 100, 226-233. DOl: 10.1016/j.foodres.2017.07.010

Fatrcová-Šramková, K., Nôžková, J., Máriássyová, M., Kačániová, M. (2016). Biologically active antimicrobial and antioxidant substances in the Helianthus annuus L. bee pollen. Journal of Environmental Science and Health, Part B, 57(3), 176-181. DOl: 10.1080/03601234.2015.1108811

Guzel, A., Aksit, H., Elmastas, M., Erenler, R. (2017). Bioassay-guided isolation and identification of antioxidant flavonoids from Cyclotrichium origanifolium (Labill.) Manden and Scheng.
Pharmacognosy Magazine, 13(50), 316-320. DOl: 10.4103/0973-1296.204556

Kast, C., Kilchenmann, V., Reinhard, H., Droz, B., Lucchetti, M.A., Dübecke, A., ... Zoller, O. (2018). Chemical fingerprinting identifies Echium vulgare, Eupatorium, Cannabinum and Senecio spp. as plant species mainly responsible for pyrrolizidine alkaloids in bee-collected pollen. Food Additives and Contaminants: Part A, 35(2), 316-327. DOl: 10.1080/19440049.2017.1378443

LeBlanc, B.W., Davis, O.K., Boue, S., Delucca, A., Deeby, T. (2009). Antioxidant activity of Sonoran Desert bee pollen. Food Chemistry, 115(4), 1299-1305. https://doi.org/10.1016/j.foodchem.2009.01.055

Li, Q., Liang, X., Zhao, L., Zhang, Z., Xue, X., Wang, K." Wu, L. (2017). UPLC-Q-exactive orbitrap/MS-based lipidomics approach to characterize lipid extracts from bee pollen and their in vitro anti-inflammatory properties. Journal of Agricultural and Food Chemistry, 65(32), 6848-6860. D0l: 10.1021/acs. jafc.7b02285

Lobo, V., Patil, A., Phatak, A., Chandra, N. (2010). Free radicals, antioxidants and functional foods: impact on human health. Pharmacognosy Reviews, 4(8), 118-126. DOl: 10.4103/0973-7847.70902

Lv, H., Wang, X., He, Y., Wang H., Suo, Y. (2015). Identification and quantification of flavonoid aglycones in rape bee pollen from Qinghai-Tibetan Plateau by HPLC-DAD-APCI/MS, Journal of Food Composition and Analysis, 38, 49-54. https://doi.org/10.1016/j. jfca.2014.10.011

Morgano, M.A., Martins, M.C.T., Rabonato, L.C., Milani, R.F., Yotsuyanagi, K., Rodriguez-Amaya, D.B. (2012). A comprehensive investigation of the mineral composition of Brazilian bee pollen: geographic and seasonal variations and contribution to human diet. Journal of the Brazilian Chemical Society, 23(4), 727-736. http:// dx.doi.org/10.1590/S0103-50532012000400019

Nagai, T., Inoue, R., Suzuki, N., Tanoue, Y., Kai, N., Nagashima, T. (2007). Antihypertensive activities of enzymatic hydrolysates from honeybee-collected 


\section{J. APCL. SUL. UOL. 65 NO. 12021}

pollen of Cistus ladaniferus. Journal of Food, Agriculture and Environment, 5(3-4), 86-89. https://doi. org/10.1234/4.2007.1044

Negrão, A.F., \& Orsi, R.O. (2018). Harvesting season and botanical origin interferes in production and nutritional composition of bee pollen. Annals of the Brazilian Academy of Sciences, 991), 325-332. DOl: 10.1590/0001-3765201720150192

Nna, V.U., Abu Bakar, A.B., Md Lazin, M.R.M.L., Mohamed, M. (2018). Antioxidant, anti-inflammatory and synergistic anti-hyperglycemic effects of Malaysian propolis and metformin in streptozotocininduced diabetic rats. Food and Chemical Toxicology, 120, 305-320. DOl: 10.1016/j.fct.2018.07.028

Pascoal, A., Rodrigues, S., Teixeira, A., Feás, X., Estevinho, L.M. (2014). Biological activities of commercial bee pollens: antimicrobial, antimutagenic, antioxidant and anti-inflammatory. Food and Chemical Toxicology, 63, 233-239. DOl: 10.1016/j. fct.2013.11.010

Pillaiyar, T., Manickam, M., Namasivayam, V. (2017). Skin whitening agents: medicinal chemistry perspective of tyrosinase inhibitors. Journal of Enzyme Inhibition and Medicinal Chemistry, 32(1), 403-425. DOl: 10.1080/14756366.2016.1256882

Rao, V., Kiran, S.D.V.S., Rohini, P., Bhagyasree, P. (2017). Flavonoid: a review on naringenin. Journal of Pharmacognosy Phytochemistry, 6(5), 2778-2783.
Sun, L., Guo, Y., Zhang, Y., Zhuang, Y. (2017). Antioxidant and anti-tyrosinase activities of phenolic extracts from rape bee pollen and inhibitory melanogenesis by cAMP/MITF/TYR pathway in B16 mouse melanoma cells. Frontiers in Pharmacology, 8, 104. DOl: 10.3389/fphar.2017.00104

Uivarosi, V., Badea, M., Olar, R., Velescu, B. (2016). Synthesis and characterization of a new complex of oxovanadium (IV) with naringenin, as potential insulinomimetic agent. Farmacia, 64(2), 175-180.

Wang, Z., Kanda, S., Shimono, T., Enkh-Undraa, D., Nishiyama, T. (2018). The in vitro estrogenic activity of the crude drugs found in Japanese herbal medicines prescribed for menopausal syndrome was enhanced by combining them. BMC Complementary and Alternative Medicine, 18(1), 107. DOl: 10.1186/ s12906-018-2170-4

WU, Y.D., \& Lou, Y.J. (2007). A steroid fraction of chloroform extract from bee pollen of Brassica campestris induces apoptosis in human prostate cancer PC-3 cells. Phytotherapy Research, 27(11), 10871091. DOl: 10.1002/ptr.2235

Zhang, H., Wang, X., Wang, K., Li, C. (2015). Antioxidant and tyrosinase inhibitory properties of aqueous ethanol extracts from monofloral bee pollen. Journal of Apicultural Science, 59(1), 119-128. https://doi. org/10.1515/jas-2015-0013 
KHONGKRrRt et hl. Antioxidant activity of mimosa bee pollen

Supplement 1: ${ }^{1} \mathrm{H}$ - and ${ }^{13} \mathrm{C}-\mathrm{NMR}$ of naringenin in $\mathrm{CD}_{3} \mathrm{OD}$

S1.1: ${ }^{1} \mathrm{H}-\mathrm{NMR}$ peak data at chemical shift (ठ), 2.0-8.0 ppm in length

S1.2: ${ }^{13} \mathrm{C}-\mathrm{NMR}$ peak data at chemical shift $(\delta), 40-200 \mathrm{ppm}$ in length

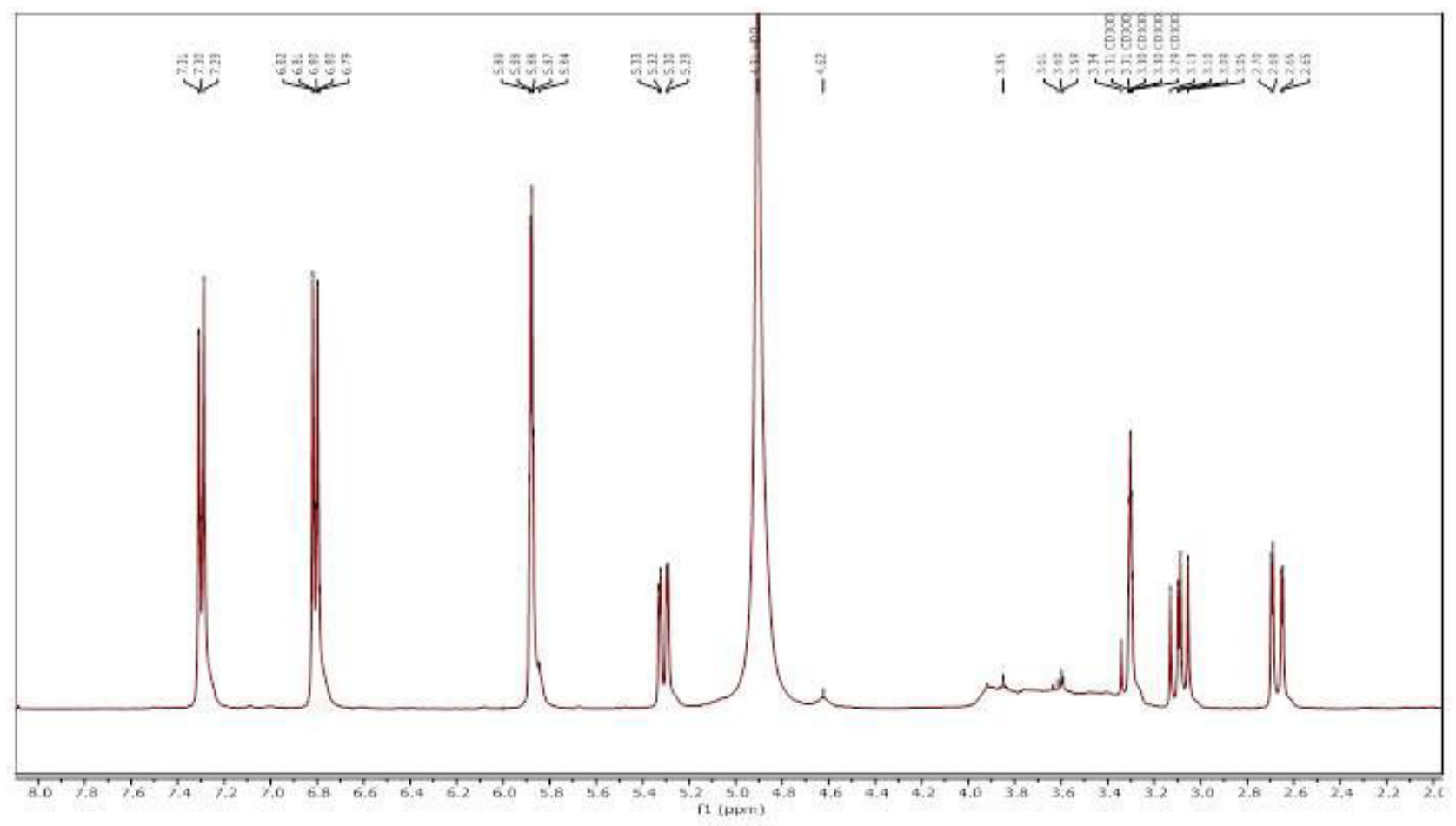

$(\mathrm{S} 1.1)$

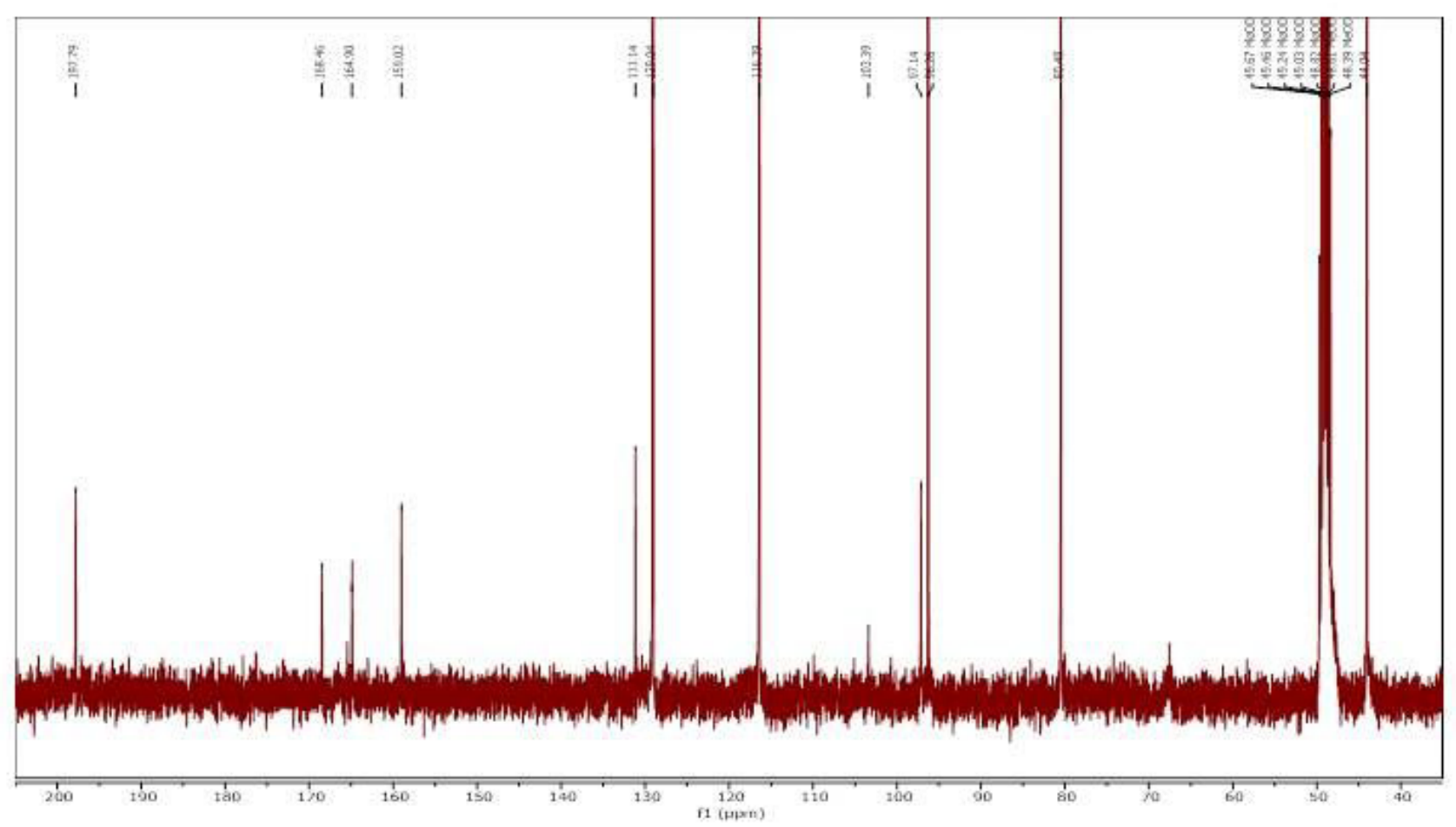

$(\mathrm{S} 1.2)$

8? 
Supplement 2: ${ }^{1} \mathrm{H}$ - and ${ }^{13} \mathrm{C}-\mathrm{NMR}$ of fraction number DCMMBP3-1 in $\mathrm{CD}_{3} \mathrm{OD}$

S2.1: ${ }^{1} \mathrm{H}-\mathrm{NMR}$ peak data at chemical shift $(\delta), 1.0-8.0 \mathrm{ppm}$ in length

S2.2: ${ }^{13} \mathrm{C}-\mathrm{NMR}$ peak data at chemical shift $(\delta), 20-180 \mathrm{ppm}$ in length

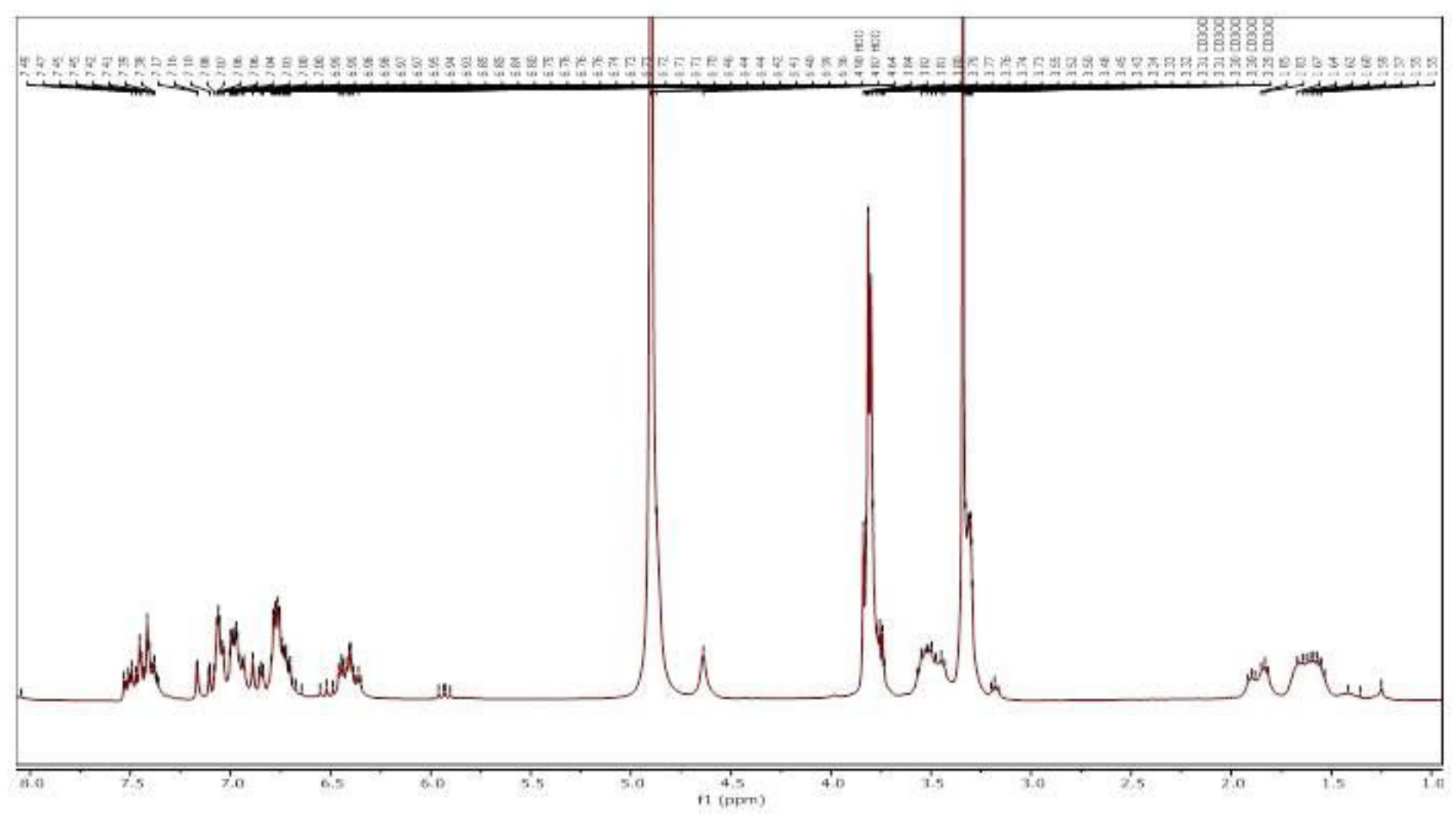

$(\mathrm{S} 2.1)$

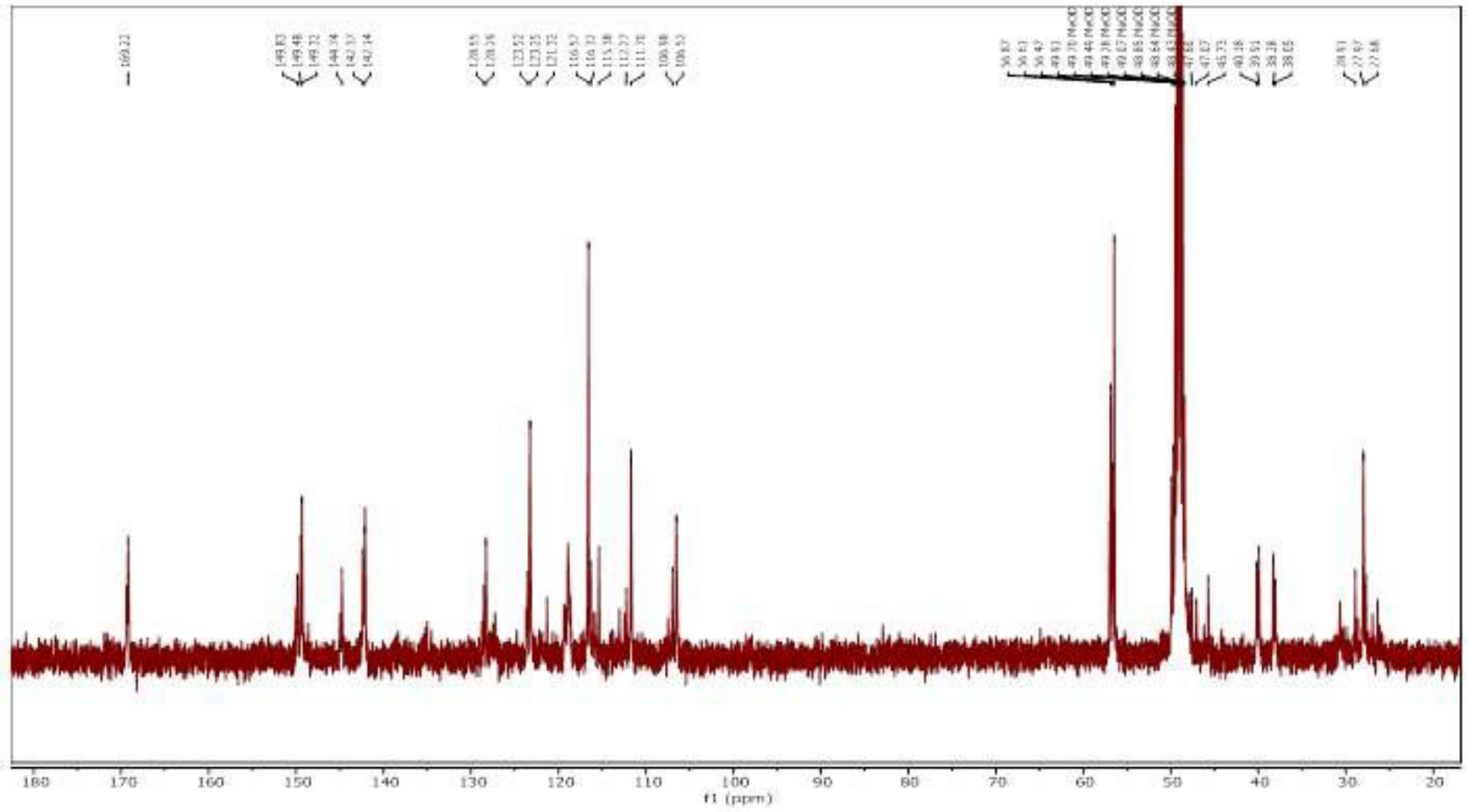

(S2.2) 